\title{
Chemical Synthesis and Immunological Evaluation of Cancer Vaccines Based on Ganglioside Antigens and $\alpha$-Galactosylceramide
}

Cecilia Romanò, ${ }^{* a}$ Hao Jiang, ${ }^{a}$ Sahar Tahvili, ${ }^{a}$ Peng Wei, ${ }^{a}$ Ulrik B. Keiding, ${ }^{a}$ Gael Clergeaud, ${ }^{\text {b }}$ Jonas R. Henriksen, ${ }^{\mathrm{b}}$ Thomas L. Andresen, ${ }^{\mathrm{b}}$ Anders E. Hansen, ${ }^{\mathrm{b}}$ Dennis Christensen, ${ }^{\mathrm{c}}$ Mads H. Clausen*a

\begin{abstract}
Affiliations
a. Center for Nanomedicine \& Theranostics, Department of Chemistry, Technical University of Denmark, Kemitorvet 207, 2800 Kgs. Lyngby, Denmark

b. Department of Health Technology, Section for Biotherapeutic Engineering and Drug Targeting, Technical University of Denmark, Ørsteds Plads, 2800 Kgs Lyngby, Denmark

c. Statens Serum Institut, Department of Infectious Disease Immunology, Artillerivej 5, 2300 Copenhagen S, Denmark
\end{abstract}

\begin{abstract}
iNKT cells - often referred as the "Swiss Army knife" of the immune system - have emerged as central players in cancer vaccine therapies. Glycolipids activating iNKT cells, such as $\alpha$-galactosylceramide ( $\alpha$ GalCer), can enhance the immune response against co-delivered cancer antigens and have been applied in the design of self-adjuvanting anti-tumor vaccines. In this context, this work focuses on the chemical synthesis of ganglioside tumor-associated carbohydrate antigens (TACAs), namely GM3 and (Neu5Gc)GM3 antigens, their conjugation to aGalCer, and their formulation into liposomes as an efficient platform for their in vivo delivery. Liposomes containing GM3- $\alpha$ GalCer, (Neu5Gc)GM3- $\alpha$ GalCer, and equimolar amounts of the two conjugates have been fully characterized and their ability to activate iNKT cell has been confirmed in vitro. Finally, the candidates were tested in in vivo immunization studies, demonstrating an ability to induce both $\mathrm{T}_{H} 1$ and $\mathrm{T}_{\mathrm{H}} 2$ cytokines further leading to the production of all subclasses of IgG antibodies. Notably, the study also demonstrated that serum antibodies raised against the two TACAs alone and in combination were cross-reactive. This finding has consequences for future vaccine designs - even if a highly tumor-selective antigen is chosen, the resulting antibody response may be broader than anticipated.
\end{abstract}

\section{Introduction}

Since their discovery in the early 1990s and the observation of their striking anti-tumor activity, ${ }^{[1,2]}$ invariant natural killer $\mathrm{T}$ (iNKT) cells have been considered an attractive target in cancer 
immunotherapy. ${ }^{[3-5]}$ iNKT cells harbor characteristics of both natural killer (NK) and T cells, thus uniquely placing themselves at the interface between innate and adaptive immunity, and orchestrate the generation of a range of immune responses via the recognition of glycolipids presented by the nonpolymorphic MHC class I-like CD1d protein. ${ }^{[6]} \alpha$-Galactosylceramide ( $\alpha$ GalCer) is the prototypical agonist for iNKT cells. ${ }^{[7]}$ To carry out its function, $\alpha$ GalCer first associates with CD1d in antigen-presenting cells (APCs), then the $\alpha$ GalCer/CD1d cell surface complex is engaged by the iNKT T cell receptor (TCR) to form the active TCR/ $\alpha$ GalCer/CD1d ternary complex of which the X-ray crystal structures, both mouse and human, were solved in 2005. ${ }^{[8-10]}$ CD1d binds $\alpha$ GalCer by hosting its two lipid chains within two hydrophobic pockets $A^{\prime}$ and $F^{\prime}$. In this way, the sugar moiety is carefully anchored by a series of intermolecular hydrogen bonds and extends above the surface of the lipid binding grooves, thus ensuring recognition by the TCR of iNKT cells. The binding is controlled by contacts between the $\alpha 1$ CD1d helix and the TCR Complementarity Determining Regions (CDR), which interact with the 3-OH and 4-OH of galactose and establish hydrogen bond networks with the $2-\mathrm{OH}$ of the sugar and the $3^{\prime}-\mathrm{OH}$ of the phytosphingosine chain. ${ }^{[11,12]}$ Stimulated iNKT cells rapidly produce copious amounts of $T_{H} 1, T_{H} 2$, and $T_{H} 17$-type cytokines, thus shaping the immune response generated by other effector cells, i.e. transactivation of NK cells, stimulation of $\mathrm{DCs}$, activation of $\mathrm{CD} 4^{+}, \mathrm{CD} 8^{+} \mathrm{T}$ cells, and maturation of $\mathrm{B}$ cells. ${ }^{[13]}$ Although promising, the use of $\alpha \mathrm{GalCer}$ alone for clinical therapy has not yet been successful due to cytokine antagonism effect and induction of iNKT cell anergy upon repeated $\alpha$ GalCer administration. ${ }^{[14]}$ Because of the limited effects of $\alpha$ GalCer in clinical studies, research has also focused on the development of $\alpha$ GalCer analogs with more distinct iNKT cell activating properties - i.e. $T_{H} 1 / T_{H} 2$ skewing, ${ }^{[11]}$ on the optimization of delivery systems e.g. liposomes, ${ }^{[15,16]}$ and on the use of $\alpha$ GalCer as a "universal helper" in vaccine development. ${ }^{[17,18]}$ In particular, the adjuvant properties of $\alpha$ GalCer have gained a substantial interest in glycoimmunology as a way to overcome the natural immunotolerance towards carbohydrate antigens. From the promising results obtained in the context of carbohydrate-based vaccines against $S$. pneumoniae infection, ${ }^{[19]}$ the conjugation of $\alpha$ GalCer to tumor-associated carbohydrate antigens (TACAs) has remarkably demonstrated the ability to break tolerance against this class of poor immunogens, thus directing research towards novel, fully synthetic cancer vaccines. In this context, notable approaches include reports by Yin et al[20] and Broecker et $a^{[21]}$ exploring, respectively, the use of sialyl Tn (sTn) and $\mathrm{Tn}$ antigen in conjugation with $\alpha$ GalCer and their formulation into liposomes, to induce robust and specific anti-sTn and anti-Tn IgG antibody responses. More recently, the field of TACA- $\alpha$ GalCer conjugates was also extended to the GM3 ganglioside antigen by a contribution from Yin et al. ${ }^{[22]}$ Specifically, the class of ganglioside TACAs, sialylated glycosphingolipids overexpressed in neuroectoderm-derived cancers (e.g. melanoma, small cell 
lung carcinoma (SCLC), neuroblastoma), often correlates with tumor aggressiveness, ${ }^{[23]}$ and has received attention as a valuable immunotherapeutic target for cancer treatment, both in passive and active immunotherapeutic approaches. ${ }^{[24]}$ The GM3 ganglioside has been identified in a number of metastatic cell lines, generally in a higher surface density in comparison to its distribution in normal tissues. ${ }^{[25,26]}$ More interestingly, the structurally similar (Neu5Gc)GM3 ganglioside is almost undetectable in normal human tissues, but it is highly expressed in several human cancer cells, ${ }^{[27,28]}$ making it an excellent target for antibody therapies and cancer vaccine development. ${ }^{[29-31]}$ This unique characteristic of (Neu5Gc)GM3 is the result of a deletion in the gene encoding the key enzyme for Neu5Gc synthesis (CMP-NeuAc hydroxylase), ${ }^{[32,33]}$ which has made humans unable to produce Neu5Gc glycoconjugates. The incorporation of Neu5Gc in human cancers is thus attributed to dietary Neu5Gc from meat and dairy products. $^{[34]}$ With these premises, we have been interested in developing the synthesis of GM3 and (Neu5Gc)GM3 conjugates with $\alpha$ GalCer, with the objective of obtaining fully synthetic vaccine constructs which could be formulated in liposomes, an effective system to ensure co-delivery of antigen and adjuvant to the same APC. Herein we present the straightforward and efficient chemical synthesis of the desired conjugates 1 and $\mathbf{2}$ (Figure 1), combining improved approaches in both ganglioside and aGalCer chemistry. Furthermore, we describe the liposomal formulation of our GM3- $\alpha$ GalCer and (Neu5Gc)GM3- $\alpha$ GalCer constructs, and their immunological evaluation in vitro and in vivo.

\section{Results and discussion}

\section{Chemical synthesis of GM3- $\alpha$ GalCer 1 and (Neu5Gc)GM3- $\alpha$ GalCer 2}

The synthesis of TACA- $\alpha$ GalCer constructs 1 and $\mathbf{2}$ required the preparation of the suitably aminefunctionalized $\alpha$ GalCer 5 and the NHS-ester equipped GM3 and (Neu5Gc)GM3 gangliosides, compounds 3 and 4, respectively (Figure 1). $\alpha$ GalCer 5 is functionalized at position C-6" with a 6-carbon amino linker, a modification that ensures retention of its adjuvant activity, ${ }^{[35]}$ while carrying a handle for derivatization. Similarly, both ganglioside TACAs are equipped with an ethanolamine linker at the anomeric position, further extended by an $\mathrm{N}$-succinimidyl glutarate moiety.

Different approaches have been developed previously for the synthesis of $\alpha$ GalCer and its derivatives, specifically addressing the low yield and poor selectivity during glycosylation to introduce the relatively unreactive ceramide. Notably, most successful approaches involve glycosylation with azide-protected phytosphingosine, followed by post-glycosylation acylation to introduce the fatty acid chain. ${ }^{[11,36,37]}$ 
Conversely, protocols which directly react the acylated phytosphingosine generally suffer from low reaction yields and poor $\alpha$ : $\beta$ selectivities when employing (benzoyl) esters as temporary protecting groups for the phytosphingosine diol, ${ }^{[38-40]}$ thus generally requiring the introduction of silyl ether protecting groups. ${ }^{[19,41]}$ In our case, the synthesis of the glycolipid was planned to involve direct glycosylation of the acylated phytosphingosine moiety 7 , equipped with benzyl ether groups to ensure higher reactivity, while allowing higher synthetic flexibility.

Regarding the preparation of ganglioside TACAs, GM3 and (Neu5Gc)GM3, the stereoselective and high yielding preparation of the trisaccharide scaffold was planned to be achieved by glycosylation of benzyl ether protected lactosyl diol $\mathbf{1 0}$ and thioglycoside sialyl donors $\mathbf{8}$ and $\mathbf{9}$, respectively (Figure 1). Specifically, sialyl donors 8 and $\mathbf{9}$ were synthesized as the less common C-2 benzyl ester derivatives, instead of the C2 methyl esters, in order to simplify the deprotection of the final $\alpha$ GalCer conjugates.

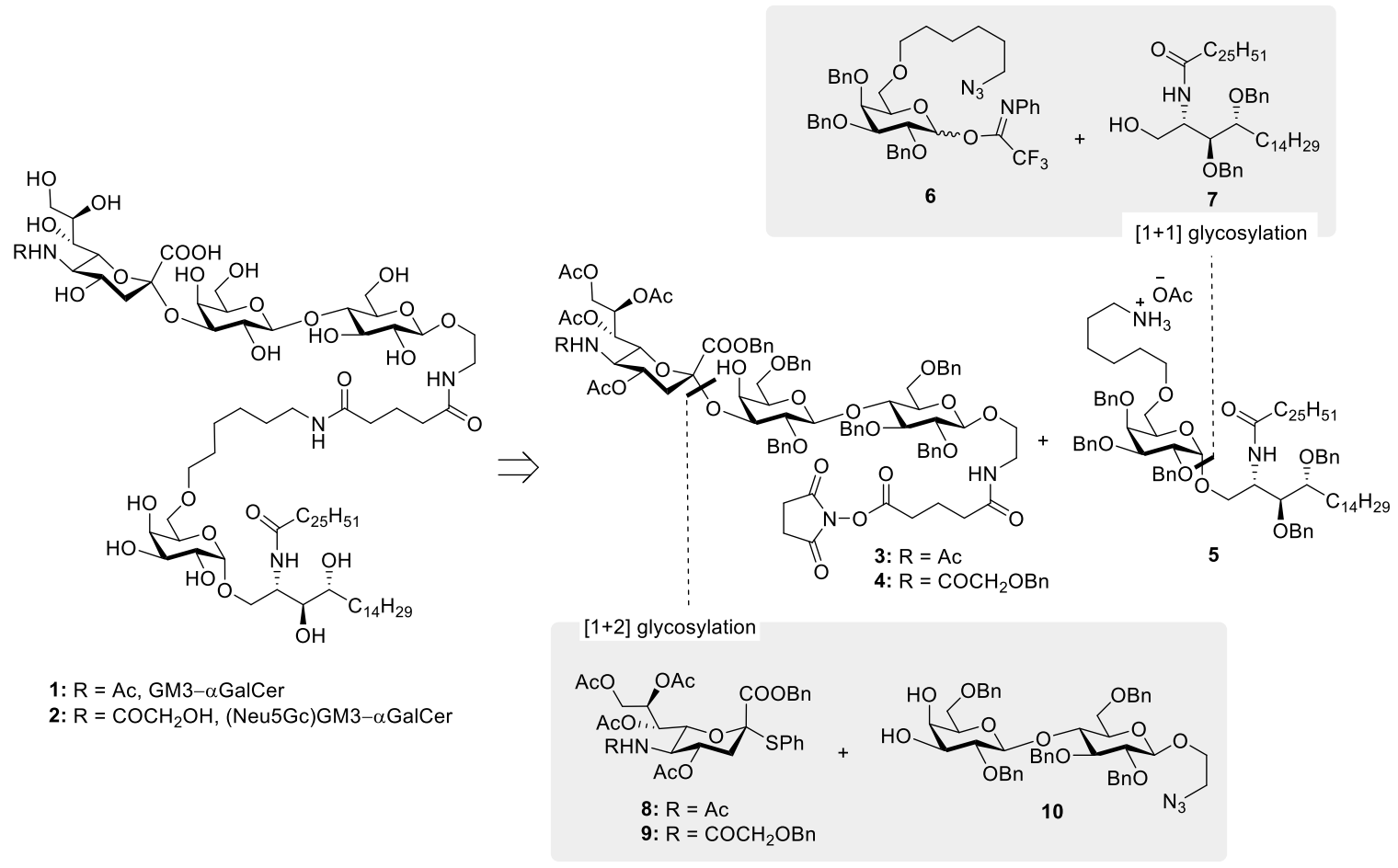

Figure 1: Global scheme for the synthesis of $\mathbf{1}$ and $\mathbf{2}$

The synthesis of $\alpha$ GalCer 5 (Scheme 1) started with the preparation of the acylated phytosphingosine moiety. Phytosphingosine was initially treated with $\mathrm{N}$-(hexacosanoyloxy)succinimide ${ }^{[42]}$ and $\mathrm{Et}_{3} \mathrm{~N}$ in $\mathrm{THF}$ under heating, then the primary $\mathrm{OH}$ group was selectively tritylated (trityl chloride, DMAP, pyridine, $80^{\circ} \mathrm{C}$ ) to afford compound $\mathbf{1 1}$ in $\mathbf{4 6 \%}$ yield over two steps. To our delight, benzylation of the two free hydroxyl 
groups on the phytosphingosine scaffold with benzyl bromide and $\mathrm{NaH}$ in DMF yielded the desired benzyl protected compound 12 in $87 \%$ yield and without formation of the $\mathrm{N}$-benzylated byproduct. To the best of our knowledge, this is the first example of preparation of a benzyl ether protected and acylated phytosphingosine that does not require the use of azide-phytosphingosine or further manipulations of the ceramide scaffold. Removal of the trityl protecting group proceeded uneventfully by treatment with p-toluenesulfonic acid in $\mathrm{CH}_{2} \mathrm{Cl}_{2} / \mathrm{MeOH}(\rightarrow 7,84 \%)$. With the desired acylated sphingosine 7 in hand, attention was devoted to the synthesis of the galactoside moiety with the C- 6 alkylation of thioglycoside $13^{[43]}$ carried out under basic conditions in the presence of 6-chlorohexyl 4-methylbenzenesulfonate. ${ }^{[44]}$ The reaction afforded compound $\mathbf{1 4}$ in 74\% yield. Nucleophilic substitution to introduce the azide was performed with $\mathrm{NaN}_{3}$ in DMF under heating $(\rightarrow \mathbf{1 5}, 84 \%)$. A first glycosylation attempt with thioglycoside 15 and benzylated ceramide 7 was carried out in the presence of $\mathrm{NIS} / \mathrm{TfOH}$ at $-20{ }^{\circ} \mathrm{C}$ in THF/Et $2 \mathrm{O}$. The reaction yielded the desired product 17 in 77\% yield, although as a 2:1 $\alpha: \beta$ mixture. While the procedure allowed access to the desired $\alpha$ GalCer scaffold, a more efficient glycosylation was investigated. Namely, 15 was converted to its corresponding $N$-phenyl 2,2,2-trifluoroacetimidate donor ${ }^{[45]}$ by hydrolysis of the thioglycoside moiety under standard conditions (NBS, acetone $/ \mathrm{H}_{2} \mathrm{O}, \rightarrow \mathbf{1 6}, 84 \%$ ) and then reaction with 2,2,2-trifluoro- $N$-phenylacetimidoyl chloride in the presence of $\mathrm{CS}_{2} \mathrm{CO}_{3}(\rightarrow 6,85 \%)$. Gratifyingly TMSOTfpromoted glycosylation with glycosyl donor 6 and acceptor $\mathbf{7}$ at $-20{ }^{\circ} \mathrm{C}$ and in THF/Et $2 \mathrm{O}$ afforded the desired product 17 in $72 \%$ yield and with complete $\alpha$-stereoselectivity. The developed strategy thus allowed for the easy and straightforward formation of a fully protected $\alpha$ GalCer bearing an important functionalization handle (i.e. terminal azide) in only 9 reaction steps and in a global yield of $11 \%$. Further derivatization of compound $\mathbf{1 7}$ was achieved by reduction of the azide by treatment with zinc under acidic conditions, affording $\alpha$ GalCer 5 in 67\% yield.

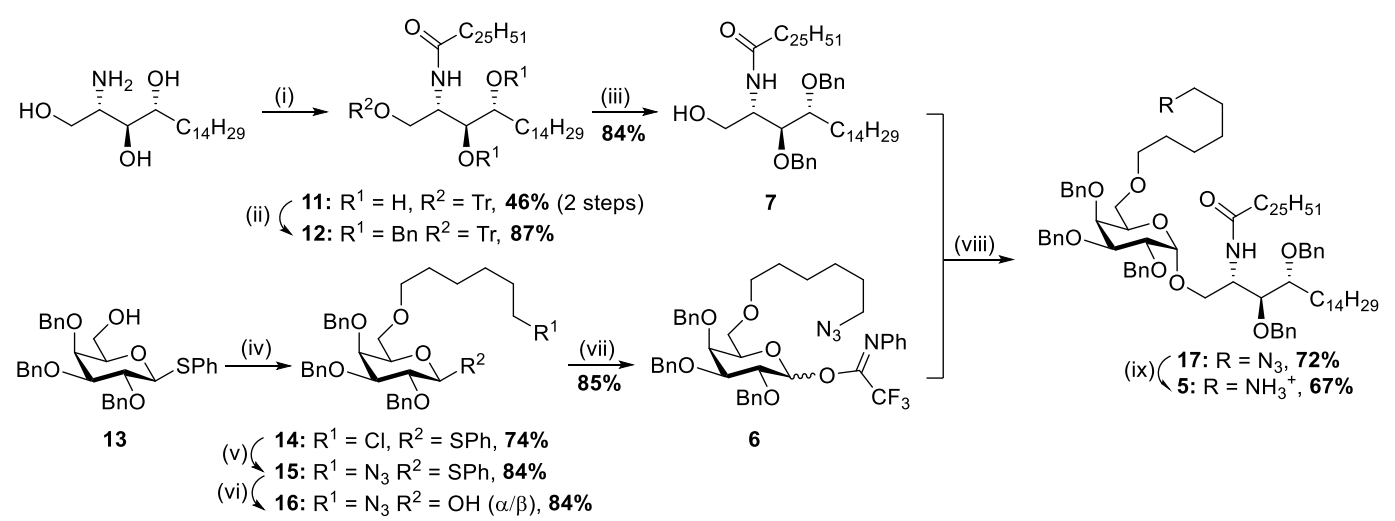

Scheme 1: (i) a. hexacosanoic acid-NHS ester, $\mathrm{Et}_{3} \mathrm{~N}, \mathrm{THF}, 50^{\circ} \mathrm{C}, \mathrm{o} / \mathrm{n}, \mathrm{b} . \mathrm{TrCl}$, pyridine, DMAP, $80{ }^{\circ} \mathrm{C}, \mathrm{o} / \mathrm{n}$; (ii) $\mathrm{BnBr}, \mathrm{NaH}(60 \%$ dispersion in mineral oil), TBAl, anhydr. DMF, $0{ }^{\circ} \mathrm{C}$ to RT, $2 \mathrm{~h}$; (iii) $p$-TsOH, $\mathrm{MeOH}, 3 \mathrm{~h}$; (iv) 6-chlorohexyl 4- 
methylbenzenesulfonate, $\mathrm{NaH}$ (60\% dispersion in mineral oil), anhydr. DMF, $0{ }^{\circ} \mathrm{C}$ to $\mathrm{RT}, 3.5 \mathrm{~h}$; (v) $\mathrm{NaN}_{3}, \mathrm{DMF}, 80^{\circ} \mathrm{C}, \mathrm{o} / \mathrm{n}$; (vi) NBS, acetone $/ \mathrm{H}_{2} \mathrm{O}, 0{ }^{\circ} \mathrm{C}, 1 \mathrm{~h}$; (vii) 2,2,2-trifluoro- $N$-phenylacetimidoyl chloride, $\mathrm{Cs}_{2} \mathrm{CO}_{3}$, anhydr. $\mathrm{CH}_{2} \mathrm{Cl}_{2}, \mathrm{RT}$; (viii) TMSOTf, anhydr. $\mathrm{THF} / \mathrm{Et}_{2} \mathrm{O},-20^{\circ} \mathrm{C}, 1 \mathrm{~h}$; (ix) Zn, $\mathrm{AcOH}, \mathrm{CH}_{2} \mathrm{Cl}_{2}, \mathrm{RT}, 45 \mathrm{~min}$.

To access the desired TACA- $\alpha$ GalCer derivatives 3 and $\mathbf{4}$, linker equipped-lactose $\mathbf{1 0}^{[46]}$ was straightforwardly prepared in 7 reaction steps and in $22 \%$ global yield following literature procedures. Sialyl donor 8 was also prepared in 4 steps ( $38 \%$ global yield, SI) exclusively as the $\alpha$-anomer with the key reaction being the $\mathrm{S}_{\mathrm{N}}$ 2-like substitution of the corresponding glycosyl chloride with thiophenol under basic conditions. Conversely, sialyl donor $\mathbf{9}$ was synthesized from $\mathbf{8}$. First, deacetylation and amide hydrolysis were achieved by treatment with methanesulfonic acid under reflux, then the crude mixture was treated with readily synthesized $O$-benzylglycolic acid succinimidyl ester under basic conditions. Finally, the obtained compound was acetylated under standard conditions $\left(\mathrm{Ac}_{2} \mathrm{O}\right.$, pyridine) to afford sialyl donor 9 in $56 \%$ over three steps. Sialyl donors 8 and 9 were reacted with lactose acceptor 10 in the presence of $\mathrm{IBr} / \mathrm{AgOTf}$ in $\mathrm{CH}_{3} \mathrm{CN} / \mathrm{CH}_{2} \mathrm{Cl}_{2}$ at $-78{ }^{\circ} \mathrm{C}$ and $-40{ }^{\circ} \mathrm{C}$, ${ }^{[47]}$ respectively. Both glycosylations afforded the desired products 18 and 19 in high yields, 85\% and 71\% respectively, with complete stereo- and regioselectivity. The developed protocols for accessing the GM3 and (Neu5Gc)GM3 scaffolds also reduced the number of glycosylation steps to only one by making use of a suitably protected lactose building block, as opposite to recent reports involving more lengthy approaches. ${ }^{[22]}$ Moreover, both glycosylation reactions proceeded in high yields even in the presence of the natural acetamide functionality on the sialic acid donor, thus greatly simplifying the number of manipulations required following glycosylation. Selective reduction of the azide moiety proceeded smoothly when both compounds $\mathbf{1 8}$ and $\mathbf{1 9}$ were treated with zinc under acidic conditions and subsequently reacted with readily prepared disuccinimidyl glutarate ${ }^{[48]}$ in the presence of $\mathrm{Et}_{3} \mathrm{~N}$ to afford the $\mathrm{N}$-hydroxylsuccinimide functionalized derivatives $\mathbf{3}$ and $\mathbf{4}$ in $\mathbf{7 9 \%}$ and $67 \%$ yield, respectively. Conjugation with aGalCer 5 proceeded uneventfully and promoted by the addition of $\mathrm{Et}_{3} \mathrm{~N}(\rightarrow \mathbf{2 0}, \mathbf{7 4 \%} \rightarrow \mathbf{2 1}, \mathbf{8 0 \%}$ ) to yield the desired GM3 and (Neu5Gc)GM3 scaffolds covalently linked to $\alpha$ GalCer. While initial deprotections were carried out by first removing the acetyl ester groups under Zemplén conditions ( $\mathrm{MeONa}, \mathrm{MeOH}$ ) and subsequent removal of the benzyl ether and benzyl ester groups by hydrogenolysis $\left(\mathrm{H}_{2}, 5 \% \mathrm{Pd} / \mathrm{C}\right)$, it was later found that inverting the order of the reactions afforded cleaner reactions and higher yield, allowing the isolation of compound $\mathbf{1}$ and $\mathbf{2}$ in $88 \%$ and $85 \%$ yield, respectively. 


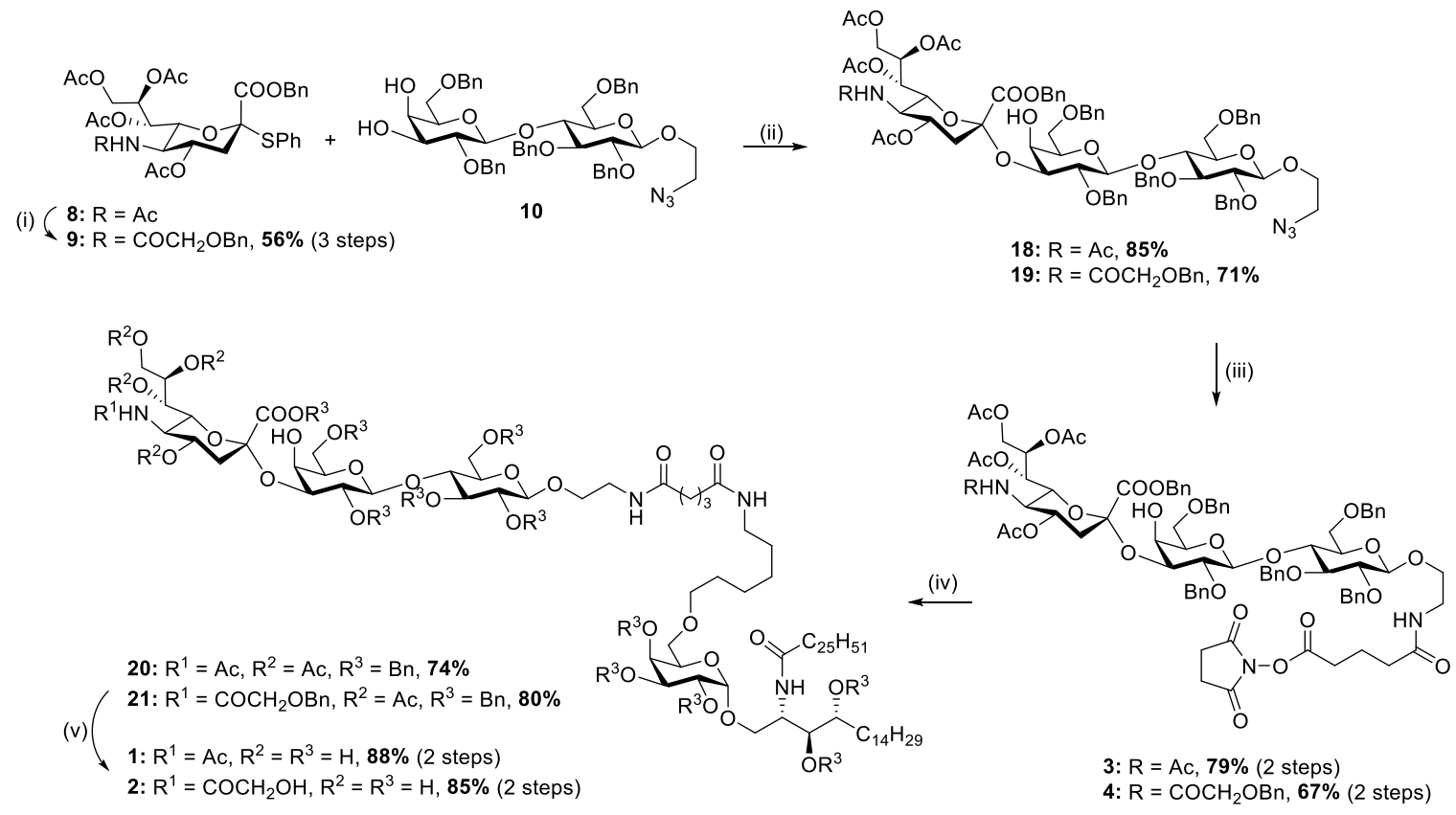

Scheme 2: (i) a. $\mathrm{MsOH}$, anhydr. $\mathrm{MeOH}, 75^{\circ} \mathrm{C}, \mathrm{o} / \mathrm{n}$, b. O-benzylglycolic acid $\mathrm{NH}$-ester, $\mathrm{CH}_{3} \mathrm{CN} / \mathrm{H}_{2} \mathrm{O}, \mathrm{RT}, 2 \mathrm{~h}, \mathrm{c}$. Ac $2 \mathrm{O}, \mathrm{pyridine}, \mathrm{RT}$, o/n; (ii) IBr/AgOTf, anhydr. $\mathrm{CH}_{3} \mathrm{CN} / \mathrm{CH}_{2} \mathrm{Cl}_{2}, 3 \AA \mathrm{AS},-78^{\circ} \mathrm{C}$ for $18,-40{ }^{\circ} \mathrm{C}$ for $19,2 \mathrm{~h}$; (iii) a. $\mathrm{Zn}, \mathrm{AcOH}$, anhydr. $\mathrm{CH}_{2} \mathrm{Cl}_{2}, \mathrm{RT}, 1 \mathrm{~h}, \mathrm{~b}$. disuccinimidyl glutarate, anhydr. DMF, Et ${ }_{3} \mathrm{~N}, \mathrm{RT}, 2$ h; (iv) 5, Et ${ }_{3} \mathrm{~N}$, anhydr. DMF, RT, 4 h; (v) a. $\mathrm{H}_{2}, \mathrm{Pd} / \mathrm{C}$ (5\% wt.), AcOH, EtOH, RT, o/n, b. MeONa, MeOH, $\mathrm{H}_{2} \mathrm{O}, \mathrm{RT}, \mathrm{o} / \mathrm{n}$.

\section{Liposomal formulations}

Conjugates 1 and 2 were formulated as liposomes. While presenting the GM3 and (Neu5Gc)GM3 TACAs in a multivalent manner, this type of formulation can itself contribute in shaping the immune response in vivo: when administered to mice (either via subcutaneous $(s c)$ injection or oral uptake) smaller lipid vesicles $(<150 \mathrm{~nm})$ tend to promote the development of a $\mathrm{T}_{\mathrm{H}} 2$ response, whereas larger lipid vesicles $(>$ $200 \mathrm{~nm}$ ) are able to shift the response towards the production of IFN- $\gamma$, thus a typical $\mathrm{T}_{H} 1$ response. ${ }^{[49,50]}$ The different activity is proposed to be related to differences in the trafficking of the vesicles by APCs, with small liposomes being transported to the late endosomes and larger ones to early endosomes.

Size-defined liposomes containing either conjugate $\mathbf{1}$ (I), conjugate $\mathbf{2}$ (II), equimolar amounts of $\mathbf{1}$ and $\mathbf{2}$ (III), or equimolar amounts of the GM3 ganglioside and $\alpha$ GalCer (IV) were prepared by lipid extrusion and subsequently characterized (SI). The liposomes contained 1,2-diastearoyl-sn-glycero-3-phosphocholine (DSPC) and cholesterol (Chol) (Table 1) and were extruded through $200 \mathrm{~nm}$ polycarbonate filters. The physiochemical properties of each liposomal formulation were evaluated by dynamic light scattering (DLS) confirming a homogeneous particle population with an approximate size of $200 \mathrm{~nm}$ and small polydispersity index (PDI), and by zeta potential measurement, showing a negative surface charge in all groups I-IV. The contents of the liposomes were further analyzed by RP-HPLC-MS/MS to evaluate the 
recovery of each individual component and ensure that $3 \mu \mathrm{g}$ of GM3 or (Neu5Gc)GM3 antigen could be administered to each animal.

\begin{tabular}{|l|l|l|l|}
\hline Liposomes & Compound(s) & Formulation & Mol Ratio \\
\hline I & GM3- $\alpha$ GalCer (1) & DSPC:Chol:1 & $58.2: 38.9: 2.9$ \\
\hline II & (Neu5Gc)GM3- $\alpha$ GalCer (2) & DSPC:Chol:2 & $58.2: 38.9: 2.9$ \\
\hline III & Equimolar of (1) and (2) & DSPC:Chol:1:2 & $56.2: 38: 2.9: 2.9$ \\
\hline IV & GM3 and $\alpha G a l C e r$ & DSPC:Chol:GM3: $\alpha$ GalCer & $56.2: 38: 2.9: 2.9$ \\
\hline
\end{tabular}

Table 1: Composition of liposomes I-IV

\section{Immunological evaluation}

iNKT cells can produce copious amounts of cytokines within hours following activation. This includes an initial burst in IL-4 production followed by IFN- $-{ }^{[51]}$ Moreover, iNKT cells constitutively express receptors for several cytokines such as IL-12, ${ }^{[52]}$ making them ready to quickly respond to activated APCs. The potency of liposomes I-IV was initially investigated in vitro. Bone marrow-derived dendritic cells (BMDCs) were first pulsed with either I-IV or LPS, co-cultured with iNKT cells and then incubated for 48 hours. A significant increase in IL-4 and IFN- $\gamma$ was detected when DCs and iNKT cells were activated with the liposomal formulations (Figure 2, A-B). Furthermore, iNKT cells that were co-cultured with DCs pulsed with I-IV produced significantly higher levels of both IL-4 and IFN- $\gamma$ compared to the co-culture with LPSactivated DCs. This further confirms the potential of I-IV in activating an immune response.

Next, we set out to determine whether liposomes I-IV can promote cytokine production in vivo. The levels of IL-4, IFN- $\psi$, and IL-12p70 were evaluated following the administration of liposomes I-IV in mice. Groups of six female C57BL/6 mice were immunized sc with liposomes I-IV at biweekly intervals (days 1, 15, 29) and sera were collected on days $0,14,28$, and 42 (SI, Figure S2). An additional group was instead immunized with a semisynthetic glycoconjugate composed of the (Neu5Gc)GM3 antigen and the carrier protein HSA, namely (Neu5Gc)GM3-HSA 22 (SI), emulsified in incomplete Freund's adjuvant (IFA) as a vaccine control. ${ }^{[53]}$ Group 22 followed the same immunization schedule as the groups treated with liposomes I-IV. Moreover, one group of mice remained untreated throughout the experiment to serve as negative control. To evaluate the production of IL-4, IFN- $\gamma$, and IL-12p70 cytokines in response to vaccination, sera samples were collected 24 hours after the first immunization. All groups of mice except for the mice treated with (Neu5Gc)GM3-HSA 22 produced high levels of all three cytokines compared to the untreated control mice, indicating a rapid activation of iNKT cells (Figure 2, C-E). The levels of cytokines were not different between groups I-IV. All groups of mice induced the production of higher levels of $T_{H} 1$-biasing cytokines which indicates that the vaccine candidates can promote a cytokine milieu 
leading to the activation of both $T_{H} 1$ and $T_{H} 2$ responses, with a higher potency towards stimulation of a

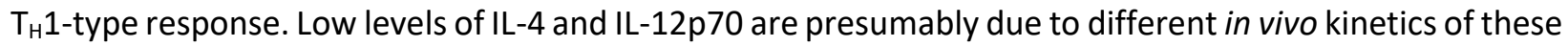
two cytokines compared to IFN- $\gamma$ following immunization.
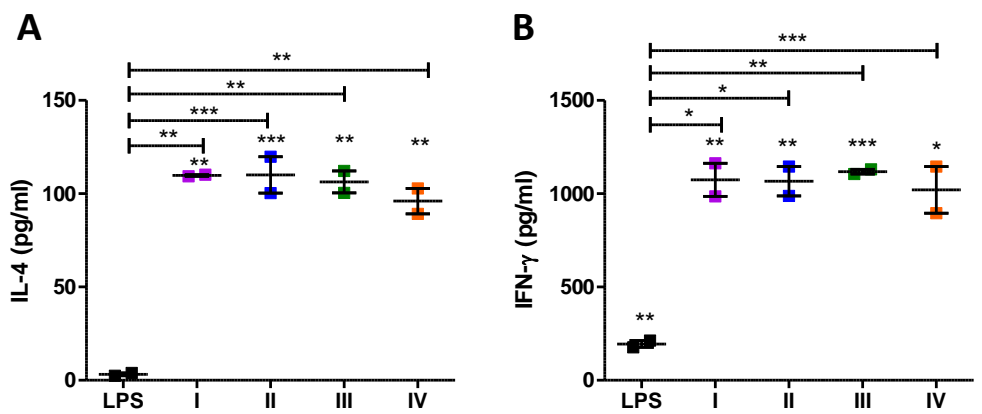

- LPS $\approx$ I: GM3- $\alpha$ GalCer $\approx$ II: (Neu5Gc)GM3- $\alpha$ GalCer $\approx$ III: GM3- $\alpha$ GalCer:(Neu5Gc)GM3$\alpha$ GalCer $₫$ IV: GM3/ $\alpha$ GalCer $₫$ compound 22 (Neu5Gc)GM3-HSA/IFA

C

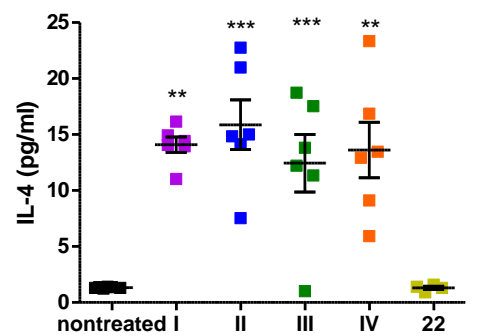

D

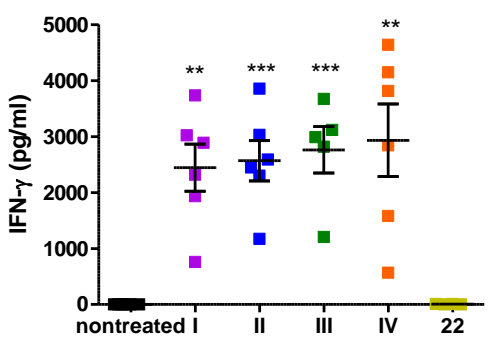

E

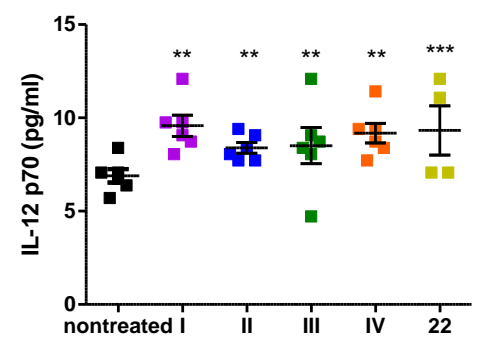

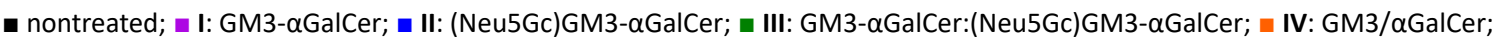
n. compound 22 (Neu5Gc)GM3-HSA/IFA

Figure 2. In vitro and in vivo production of IL-4, IFN- $y$, and IL-12 induced by the vaccine candidates in co-culture supernatant (A-

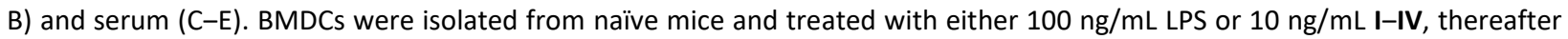
isolated iNKT cells were added to the culture. Secretion of cytokines in the supernatant was measured by cytometric bead array (CBA). The serum concentrations of cytokines were evaluated by CBA 24 hours after the first injection. The data are indicated as the average value \pm SEM. Asterisks without brackets show significant difference to the untreated control group using one-way ANOVA followed by Dunnett's multiple comparison test. Asterisks with brackets indicate significant differences to the LPS group using an unpaired two-tailed Student's t-test. ${ }^{*} P \leq 0.05,{ }^{* *} P \leq 0.01,{ }^{* * *} P \leq 0.001$.

In addition to the production of cytokines, the in vivo response of iNKT cells is characterized by the induction of a variety of activation markers such as CD25 and CD69. ${ }^{[54]}$ Mice splenocytes were analyzed by flow cytometry two days after the first immunization to evaluate the effect of the liposome groups IIII, carrying the TACA- $\alpha$ GalCer conjugates, on iNKT cells in vivo. iNKT cells were identified by staining with anti-TCR $\beta$ antibody and $m C D 1 d: \alpha G a l C e r$ tetramer. The TCR $\beta^{\text {int }} m C D 1 d: \alpha G a l C e r$ tetramer ${ }^{+}$cells were costained with anti-CD69, CD25, and IFN- $\gamma$ mAbs to identify subpopulations of activated iNKT cells (SI, Figure 
S3). Spleens from mice immunized with I and II displayed a significant increase in the percentage of iNKT cells compared to the control mice. All groups of mice that were treated with liposomes I-IV showed an increase in expression of CD25 and CD69 on iNKT cells and intracellular levels of IFN- $\gamma$, suggesting that a considerable proportion of iNKT cells had undergone the activation pathway (Figure 3, B-D). Although immunization with III did not result in a significant increase in the percentage of splenic iNKT cells, the increase in CD69, CD25, and IFN- $\gamma$ expression on cells suggests that III activated iNKT cells but was not capable of stimulating proliferation.

A

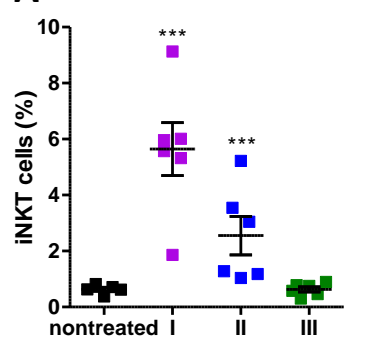

C

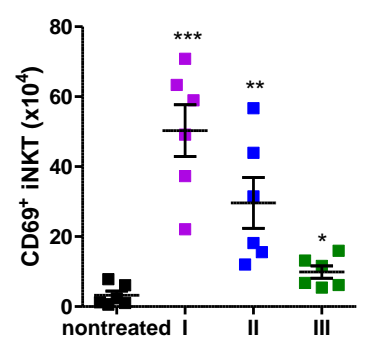

B

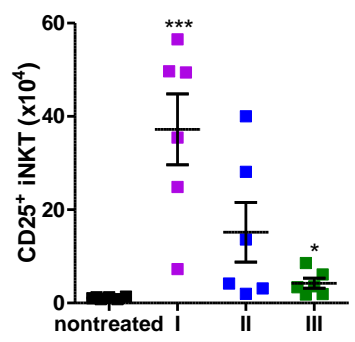

D

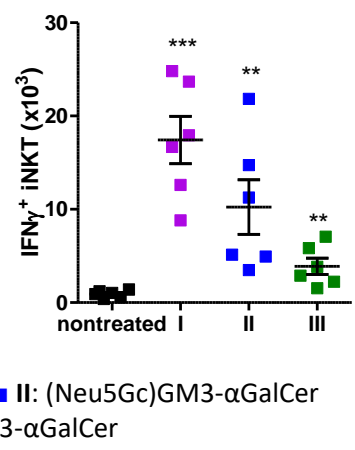

Figure 3. Liposomes I-III induced generation and activation of splenic iNKT cells. (A) Percentage of iNKT cells (TCR $\beta^{\text {int }}$ CD1d: $\alpha$ GalCer tetramer ${ }^{+}$) among total splenic cells and (B-D) absolute numbers of splenic iNKT cells with the activated phenotype $\left(\mathrm{CD} 25^{+}, \mathrm{CD} 69^{+}, \mathrm{IFN}-\gamma^{+}\right)$. Mice were immunized $s c$ and sacrificed 2 days later. The data are indicated as the average value \pm SEM of 6 mice per group. Asterisks show significant difference to the nontreated mice using one-way ANOVA followed by Dunnett's multiple comparison test. $* P \leq 0.05, * * P \leq 0.01, * * * P \leq 0.001$.

Next, it was examined whether the immunization with I-IV was capable of stimulating B cells to produce anti-GM3 or anti-(Neu5Gc)GM3 antibodies. IgM and IgG antibody responses were measured by ELISA using (Neu5Gc)GM3-HSA 22 or GM3-HSA 23 as coating antigens (experimental procedures in the SI). Mice immunized with I-IV generated carbohydrate-specific antibodies of the IgM class (Figure 4, A and C). With respect to IgG, all vaccine candidates efficiently generated an anti-IgG response, which gradually increased following the course of the experiment (Figure 4, B and D). The IgM and IgG levels on specified 
weeks are shown in Figure S4 (SI). The decrease in levels of IgM following the second and third immunization moves in parallel with the gradual increase in levels of $\lg G$, indicating an induction of isotype switching. Moreover, the immunization protocol induced an IgG response which remained high two weeks after the last injection. Mice immunized with (Neu5Gc)GM3-HSA 22 produced the highest levels of IgM and IgG as a result of activation of the helper T cell pathway due to its glycoprotein nature and the recognized effect of IFA on shaping the immune response. ${ }^{[55]}$ The IgG response following the second and third immunizations with I-III was more pronounced compared to group IV, which might be the result of the covalent bond between TACAs and $\alpha$ GalCer in the former. Moreover, both the IgM and IgG antibodies generated following immunization with formulations I and IV, containing GM3 only, cross-reacted with the (Neu5Gc)GM3-HSA coated ELISA microplates (Figure 4 and Figure S4). The same cross-reactivity was detected for the antibodies produced in mice immunized with formulations II and III, presenting the (Neu5Gc)GM3 antigen, which were found to bind to the GM3 antigen in ELISA (Figure 4 and Figure S4).

A

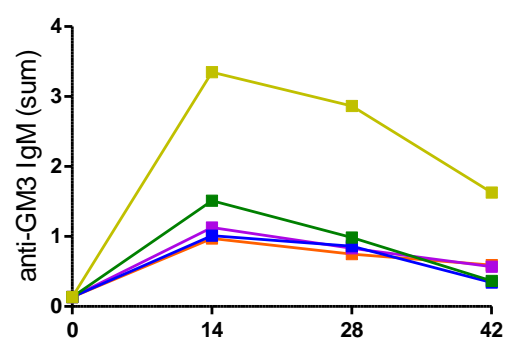

C

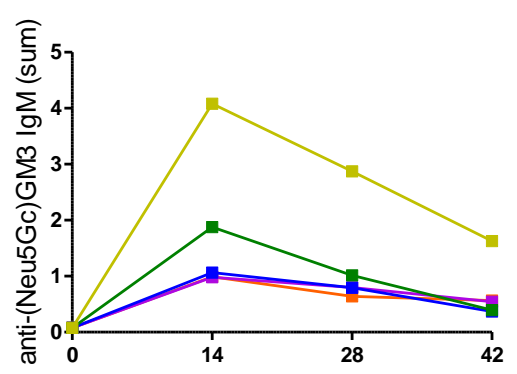

B

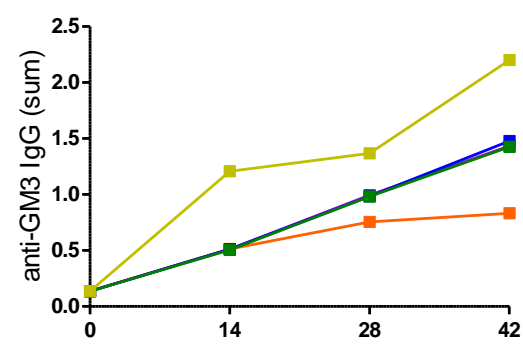

D

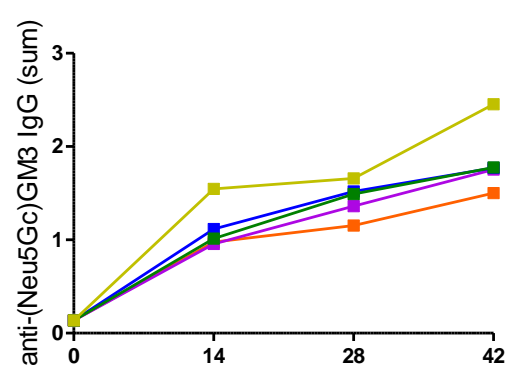

- I: GM3- $\alpha$ GalCer - II: (Neu5Gc)GM3- $\alpha$ GalCer - III: GM3- $\alpha$ GalCer:(Neu5Gc)GM3- $\alpha$ GalCer IV: GM3/ $\alpha$ GalCer 1 compound 22 (Neu5Gc)GM3-HSA/IFA

Figure 4. Stimulation of antibody production and isotype by liposomal formulations I-IV and 22. The GM3 (A-B) and (Neu5Gc)GM3 (C-D) IgM and IgG responses on day 14, 28 and 42 after immunization. Data represents mean value \pm SEM, $n=6$ for I-IV and 4 for 22 emulsified in IFA. 
The isotype distribution of IgG antibodies was also investigated. In mice, $T_{H} 2$-type responses mainly induce the generation of $\lg G 1$, while $T_{H} 1$ ones favor isotype switching to $\operatorname{lgG} 3 .{ }^{[56]}$ Mice immunized with liposomes I-III produced higher levels of anti-GM3 and anti-(Neu5Gc)GM3 IgG3 and IgG2b while displaying minimal levels of IgG1 and IgG2a (Figure 5). A similar magnitude of switching was recently reported in a similar study ${ }^{[22]}$ and can partly be explained by the suppression of the $T_{H} 2$-like response of iNKT cells by the GM3 ganglioside. ${ }^{[57]}$ Although the highest levels of $\operatorname{lgG} 1$ and $\operatorname{lgG} 2 a$ were detected in mice immunized with the conventional glycoconjugate $\mathbf{2 2}$, there was a low isotype switching to $\operatorname{lgG} 3$ and $\lg G 2 \mathrm{~b}$. This pattern of class switching following injection of a glycoprotein conjugate with IFA is likely due to the presence of IFA and the accompanying cytokine milieu.

A

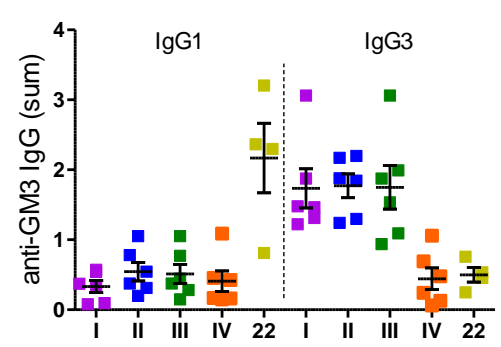

C

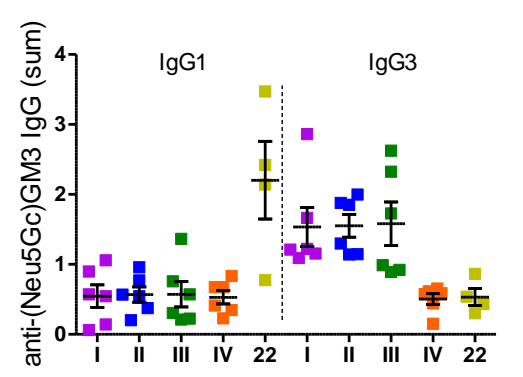

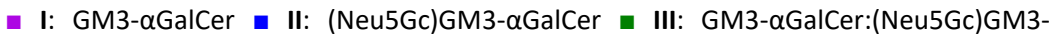
$\alpha$ GalCer $\approx$ IV: GM3/ $\alpha$ GalCer $=$ compound 22 (Neu5Gc)GM3-HSA/IFA
B

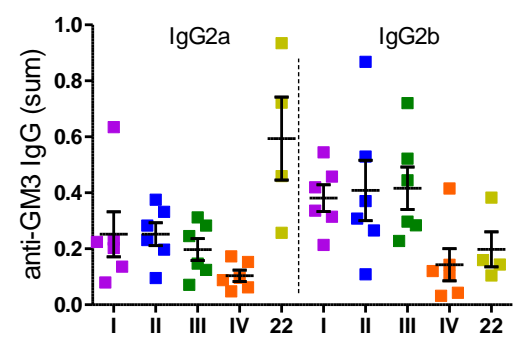

D

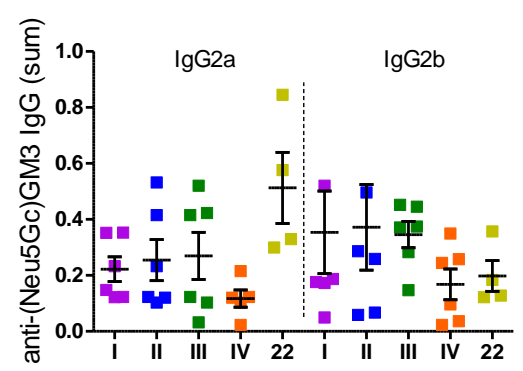

Figure 5. The GM3 (A-B) and (Neu5Gc)GM3 (C-D) specific IgG subtypes at day 42 as measured by ELISA. Mice were immunized $s c$ at biweekly intervals and sacrificed on day 42. Data are represented as the average value \pm SEM in each group. $n=6$ for I-IV and 4 for 22 emulsified in IFA.

The ability of antisera prepared on day 42 to bind to the B16F10 cell line, known to express the GM3 antigen, ${ }^{[58]}$ was determined by flow cytometry. Serum obtained from mice vaccinated with all vaccine candidates displayed significant binding to B16F10 cells (Figure 6). Immunization with liposomes I-III led to higher binding capacities (positive cells: $16.2 \%, 24.7 \%$, and $23.8 \%$, respectively) compared to group IV 
containing non-conjugated GM3 ganglioside and $\alpha$ GalCer (13.7\% positive cells). A $29.4 \%$ binding was detected in sera obtained from mice vaccinated with the protein conjugate $\mathbf{2 2}$. As mentioned previously, B16F10 cells express only GM3 antigen and not (Neu5Gc)GM3. Therefore, binding of the antibodies generated following immunization with groups II, III, and $\mathbf{2 2}$ to B16F10 cells further confirms the crossreactivity of the antibodies with the GM3 antigen.
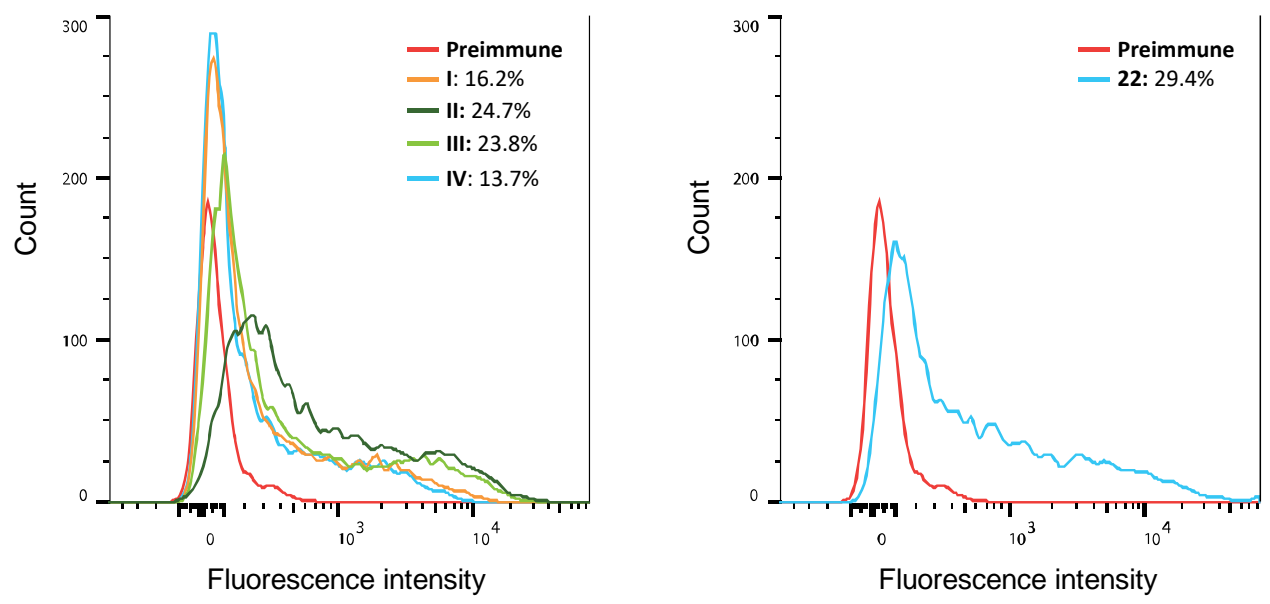

Figure 6. Binding of serum obtained from immunized mice to B16F10 cells. Pooled sera obtained from all groups of mice were incubated with B16F10 cells, and PE-conjugated anti mouse IgG was used for the detection of the binding using flow cytometry. Serum of mice before the first immunization (pre-immune) was used as the negative control.

Finally, the ability of antisera obtained by immunization to activate the complement system on the surface of B16F10 cells was evaluated. The acute monocytic leukemia THP-1 cell line that does not express GM3 and (Neu5Gc)GM3 antigens was used as the negative control. B16F10 cells were first incubated with the antisera prepared on day 42. Next, complement protein was added to the cells and the percentage of dead cells was determined. The complement cascade was efficiently activated on the surface of B16F10 cells resulting in their killing (SI, Figure S5). This result demonstrates that the antibodies produced in the immunized mice are capable of specifically binding to the surface of B16F10 cells and not to a cell line such as THP-1 which lacks expression of the specific ganglioside TACAs, GM3 and (Neu5Gc)GM3.

\section{Conclusions}

An efficient synthetic strategy for the preparation of ganglioside- $\alpha$ GalCer conjugates has been developed. In particular, a straightforward approach was applied to the synthesis of linker-functionalized $\alpha \mathrm{GalCer}$, including a key stereoselective glycosylation step with the classically poorly reactive ceramide moiety. In the same way, the desired ganglioside TACAs, namely GM3 and (Neu5Gc)GM3 were obtained in high 
yields and efficiently conjugated to $\alpha$ GalCer. Contrarily to recent approaches ${ }^{[22]}$ the developed methodology for accessing these compounds requires only one glycosylation step and, at the same time, ensures $\alpha$-selectivity.

The liposomal formulations elicited strong and consistent production of IgM and IgG. The observed isotype switching to IgG in immunized mice is presumably due to the help provided by iNKT cells and not helper T cells because the formulations did not contain any helper peptide epitope. It is well established that iNKT cells can help B cells initiate antibody responses, affinity maturation, and isotype switching. ${ }^{[15]}$ Moreover, the antibodies exhibited strong binding to the B16F10 cell line and efficient activation of the complement system on its surface.

We showed that our liposomal formulations induced production of both $T_{H} 1$ - and $T_{H} 2$-associated cytokines such as IFN- $\gamma$ and IL-4, leading to the production of all subclasses of IgG antibodies. This further emphasizes the potential of our constructs in shaping the immune response. This feature opens new venues for designing a variety of vaccine candidates by introducing elements which can be used to redirect the therapy towards either activation or suppression of the immune system.

The serum antibodies raised against the two TACAs, GM3 and (Neu5Gc)GM3 were cross-reactive. While generally considered highly specific for their designated antigen, previous screenings of 27 anti-glycan antibodies and 80 different glycans (and glycoproteins) have highlighted the cross-reactivity of several antibodies, which were thought to be highly selective. ${ }^{[59]}$ The cross-reactivity of anti-GM3 and anti(Neu5Gc)GM3 antibodies, raised by the presentation of the carbohydrate epitopes of the GM3 and (Neu5Gc)GM3 TACAs, is thus not completely surprising. This finding is an important element to consider in future carbohydrate-based cancer vaccine designs as the antibody responses might be broader than anticipated even when highly tumor-selective TACA epitopes are employed.

\section{References}

[1] T. Kawano, J. Cui, Y. Koezuka, I. Toura, Y. Kaneko, H. Sato, E. Kondo, M. Harada, H. Koseki, T. Nakayama, et al., Proc. Natl. Acad. Sci. U. S. A. 1998, 95, 5690-5693.

[2] O. Lantz, A. Bendelac, J. Exp. Med. 1994, 180, 1077-1106.

[3] Y. Zhang, R. Springfield, S. Chen, X. Li, X. Feng, R. Moshirian, R. Yang, W. Yuan, Front. Immunol. 2019, 10, 11-15.

[4] L. A. King, R. Lameris, T. D. de Gruijl, H. J. van der Vliet, Front. Immunol. 2018, 9, 1-7. 
[5] M. Bedard, M. Salio, V. Cerundolo, Front. Immunol. 2017, 8, 1-12.

[6] M. Brigl, M. B. Brenner, Annu. Rev. Immunol. 2004, 22, 817-890.

[7] E. Kobayashi, K. Motoki, T. Uchida, H. Fukushima, Y. Koezuka, Oncol. Res. 1995, 7, 529-534.

[8] D. M. Zajonc, C. Cantu, J. Mattner, D. Zhou, P. B. Savage, A. Bendelac, I. A. Wilson, L. Teyton, Nat. Immunol. 2005, 6, 810-818.

[9] M. Koch, V. S. Stronge, D. Shepherd, S. D. Gadola, B. Mathew, G. Ritter, A. R. Fersht, G. S. Besra, R. R. Schmidt, E. Y. Jones, et al., Nat. Immunol. 2005, 6, 819-826.

[10] N. A. Borg, K. S. Wun, L. Kjer-Nielsen, M. C. J. Wilce, D. G. Pellicci, R. Koh, G. S. Besra, M. Bharadwaj, D. I. Godfrey, J. McCluskey, et al., Nature 2007, 448, 44-49.

[11] A. Banchet-Cadeddu, E. Hénon, M. Dauchez, J.-H. Renault, F. Monneaux, A. Haudrechy, Org. Biomol. Chem. 2011, 9, 3080-3104.

[12] E. Girardi, D. M. Zajonc, Immunol. Rev. 2012, 250, 167-179.

[13] V. Cerundolo, J. D. Silk, S. H. Masri, M. Salio, Nat. Rev. Immunol. 2009, 9, 28-38.

[14] V. V Parekh, S. Joyce, L. Van Kaer, V. V Parekh, M. T. Wilson, D. Olivares-villagómez, A. K. Singh, L. Wu, J. Clin. Invest. 2005, 115, 2572-2583.

[15] S. Deng, L. Bai, R. Reboulet, R. Matthew, D. A. Engler, L. Teyton, A. Bendelac, P. B. Savage, Chem. Sci. 2014, 5, 1437-1441.

[16] R. Verbeke, I. Lentacker, K. Breckpot, J. Janssens, S. Van Calenbergh, S. C. De Smedt, H. Dewitte, ACS Nano 2019, 13, 1655-1669.

[17] M. Speir, I. F. Hermans, R. Weinkove, Drugs 2017, 77, 1-15.

[18] Z. Liu, J. Guo, Carbohydr. Res. 2017, 452, 78-90.

[19] M. Cavallari, P. Stallforth, A. Kalinichenko, D. C. K. Rathwell, T. M. A. Gronewold, A. Adibekian, L. Mori, R. Landmann, P. H. Seeberger, G. De Libero, Nat. Chem. Biol. 2014, 10, 950-956.

[20] X. G. Yin, X. Z. Chen, W. M. Sun, X. S. Geng, X. K. Zhang, J. Wang, P. P. Ji, Z. Y. Zhou, D. J. Baek, G. F. Yang, et al., Org. Lett. 2017, 19, 456-459.

[21] F. Broecker, S. Götze, J. Hudon, D. C. K. Rathwell, C. L. Pereira, P. Stallforth, C. Anish, P. H. 
Seeberger, J. Med. Chem. 2018, 61, 4918-4927.

[22] X.-G. Yin, J. Lu, J. Wang, R.-Y. Zhang, X.-F. Wang, C.-M. Liao, X.-P. Liu, Z. Liu, J. Guo, J. Med. Chem. 2021, 64, 1951-1965.

[23] S. Groux-Degroote, Y. Guérardel, P. Delannoy, ChemBioChem 2017, 18, 1146-1154.

[24] J. L. Daniotti, A. A. Vilcaes, V. Torres Demichelis, F. M. Ruggiero, M. Rodriguez-Walker, Front. Oncol. 2013, 3, 1-12.

[25] S. I. Hakomori, K. Handa, Glycoconj. J. 2015, 32, 1-8.

[26] M. Nishikawa, M. Kurano, T. Nitta, H. Kanoh, J. ichi Inokuchi, Y. Yatomi, Sci. Rep. 2019, 9, 1-9.

[27] J. L. Daniotti, R. D. Lardone, A. A. Vilcaes, J. L. Daniotti, Front. Oncol. 2016, 5, 1-11.

[28] Y. N. Malykh, R. Schauer, L. Shaw, Biochimie 2001, 83, 623-634.

[29] U. Krengel, P. A. Bousquet, Front. Immunol. 2014, 5, 1-11.

[30] J. Heimburg-Molinaro, M. Lum, G. Vijay, M. Jain, A. Almogren, K. Rittenhouse-Olson, Vaccine 2011, 29, 8802-8826.

[31] V. Padler-Karavani, N. Hurtado-Ziola, M. Pu, H. Yu, S. Huang, S. Muthana, H. A. Chokhawala, H. Cao, P. Secrest, D. Friedmann-Morvinski, et al., Cancer Res. 2011, 71, 3352-3363.

[32] A. N. Samraj, H. Läubli, N. Varki, A. Varki, Front. Oncol. 2014, 4, 1-13.

[33] H. H. Chou, H. Takematsu, S. Diaz, J. Iber, E. Nickerson, K. L. Wright, E. A. Muchmore, D. L. Nelson, S. T. Warren, A. Varki, Pnas 1998, 95, 11751-11756.

[34] S. Bashir, L. K. Fezeu, S. Leviatan Ben-Arye, S. Yehuda, E. M. Reuven, F. Szabo De Edelenyi, I. Fellah-Hebia, T. Le Tourneau, B. M. Imbert-Marcille, E. B. Drouet, et al., BMC Med. 2020, 18, 119.

[35] N. Kamada, H. lijima, K. Kimura, M. Harada, E. Shimizu, S. I. Motohashi, T. Kawano, H. Shinkai, T. Nakayama, T. Sakai, et al., Int. Immunol. 2001, 13, 853-861.

[36] S. Figueroa-Pérez, R. R. Schmidt, Carbohydr. Res. 2000, 328, 95-102.

[37] W. Du, J. Gervay-Hague, Org. Lett. 2005, 7, 2063-2065. 
[38] C. Xia, Q. Yao, J. Schümann, E. Rossy, W. Chen, L. Zhu, W. Zhang, G. De Libero, P. G. Wang, Bioorganic Med. Chem. Lett. 2006, 16, 2195-2199.

[39] J. M. H. Cheng, S. H. Chee, Y. Dölen, M. Verdoes, M. S. M. Timmer, B. L. Stocker, Carbohydr. Res. 2019, 486, 1-9.

[40] W. Ma, J. Bi, C. Zhao, Z. Zhang, T. Liu, G. Zhang, Bioorganic Med. Chem. 2020, 28, 1-10.

[41] J.-J. Park, J. H. Lee, S. C. Ghosh, G. Bricard, M. M. Venkataswamy, S. A. Porcelli, S.-K. Chung, Bioorganic Med. Chem. Lett. 2008, 18, 3906-3909.

[42] J. Janssens, T. Decruy, K. Venken, T. Seki, S. Krols, J. Van Der Eycken, M. Tsuji, D. Elewaut, S. Van Calenbergh, ACS Med. Chem. Lett. 2017, 8, 642-647.

[43] D. Magaud, C. Grandjean, A. Doutheau, D. Anker, V. Shevchik, N. Cotte-Pattat, J. Robert-Baudouy, Carbohydr. Res. 1998, 314, 189-199.

[44] K. Mori, Y. Shikichi, S. Shankar, J. Y. Yew, Tetrahedron 2010, 66, 7161-7168.

[45] B. Yu, H. Tao, Tetrahedron Lett. 2001, 42, 2405-2407.

[46] A. Chernyak, S. Oscarson, D. Turek, Carbohydr. Res. 2000, 329, 309-316.

[47] A. Meijer, U. Ellervik, J. Org. Chem. 2002, 67, 7407-7412.

[48] D. M. Marsden, R. L. Nicholson, M. Ladlow, D. R. Spring, Chem. Commun. 2009, 7107-7109.

[49] J. M. Brewer, L. Tetley, J. Richmond, F. Y. Liew, J. Alexander, J. Immunol. 1998, 161, 4000-7.

[50] R. A. Schwendener, Ther. Adv. Vaccines 2014, 2, 159-182.

[51] D. B. Stetson, M. Mohrs, R. L. Reinhardt, J. L. Baron, Z.-E. Wang, L. Gapin, M. Kronenberg, R. M. Locksley, J. Exp. Med. 2003, 198, 1069-1076.

[52] M. C. Leite-de-moraes, A. Hameg, A. Arnould, F. Machavoine, Y. Koezuka, E. Schneider, A. Herbelin, M. Dy, J. Immunol. 1999, 163, 5871-5876.

[53] P. O. Livingston, Immunol. Rev. 1995, 145, 147-156.

[54] L. Van Kaer, Nat. Rev. Immunol. 2005, 5, 31-42.

[55] J. C. C. Chang, J. P. Diveley, J. R. Savary, F. C. Jensen, Adv. Drug Deliv. Rev. 1998, 32, 173-186. 
[56] R. L. Coffman, B. W. P. Seymour, D. A. Lebman, D. D. Hiraki, J. A. Christiansen, B. Shrader, H. M. Cherwinski, H. F. J. Savelkoul, F. D. Finkelman, M. W. Bond, et al., Immunol. Rev. 1988, 102, 5-28.

[57] J. E. Park, D. Y. Wu, M. Prendes, S. X. Lu, G. Ragupathi, N. Schrantz, P. B. Chapman, Immunology 2008, 123, 145-155.

[58] D. Dorvignit, K. F. Boligan, E. Relova-Hernández, M. Clavell, A. López, M. Labrada, H. U. Simon, A. López-Requena, C. Mesa, S. von Gunten, Sci. Rep. 2019, 9, 1-12.

[59] J. C. Manimala, T. A. Roach, Z. Li, J. C. Gildersleeve, Glycobiology 2007, 17, 17C-23C. 